\title{
Mapping the structural connectivity between the periaqueductal gray and the cerebellum in humans
}

\author{
Alberto Cacciola ${ }^{1}\left[\right.$. Salvatore Bertino ${ }^{1}$ - Gianpaolo Antonio Basile ${ }^{1} \cdot$ Debora Di Mauro $^{1} \cdot$ Alessandro Calamuneri $^{2}$. \\ Gaetana Chillemi ${ }^{2}$ - Antonio Duca ${ }^{2}$. Daniele Bruschetta ${ }^{1}$ - Paolo Flace ${ }^{3}$. Angelo Favaloro ${ }^{1,3}$. \\ Rocco Salvatore Calabrò ${ }^{2} \cdot$ Giuseppe Anastasi $^{1} \cdot$ Demetrio Milardi $^{1,2}$
}

Received: 7 January 2019 / Accepted: 21 May 2019 / Published online: 5 June 2019

(c) The Author(s) 2019

\begin{abstract}
The periaqueductal gray is a mesencephalic structure involved in modulation of responses to stressful stimuli. Structural connections between the periaqueductal gray and the cerebellum have been described in animals and in a few diffusion tensor imaging studies. Nevertheless, these periaqueductal gray-cerebellum connectivity patterns have yet to be fully investigated in humans. The objective of this study was to qualitatively and quantitatively characterize such pathways using high-resolution, multi-shell data of 100 healthy subjects from the open-access Human Connectome Project repository combined with constrained spherical deconvolution probabilistic tractography. Our analysis revealed robust connectivity density profiles between the periaqueductal gray and cerebellar nuclei, especially with the fastigial nucleus, followed by the interposed and dentate nuclei. High-connectivity densities have been observed between vermal (Vermis IX, Vermis VIIIa, Vermis VIIIb, Vermis VI, Vermis X) and hemispheric cerebellar regions (Lobule IX). Our in vivo study provides for the first time insights on the organization of periaqueductal gray-cerebellar pathways thus opening new perspectives on cognitive, visceral and motor responses to threatening stimuli in humans.
\end{abstract}

Keywords Connectome $\cdot$ CSD $\cdot$ Diffusion MRI $\cdot$ White matter $\cdot$ Tractography

\section{Introduction}

The periaqueductal gray (PAG) is an important neuronal station situated in the mesencephalon, surrounding the Sylvian aqueduct. According to the present knowledge, it probably works as a main control station for innate and acquired responses to stressful stimuli such as fear, anxiety and pain, by coordinating and integrating appropriate vegetative and behavioral responses (Carrive 1993; Fanselow et al. 1991; Tovote et al. 2016; Walker and Carrive 2003). The current opinion is that PAG is a downstream regulatory station involved in a circuit including the prefrontal cortex (PFC),

Alberto Cacciola

alberto.cacciola0@gmail.com

1 Department of Biomedical, Dental Sciences and Morphological and Functional Images, University of Messina, Messina, Italy

2 IRCCS Centro Neurolesi “Bonino Pulejo”, Messina, Italy

3 School of Medicine, University of Bari 'Aldo Moro', Bari, Italy amygdala and hippocampus, exerting a descending control on the spinal cord (Bandler et al. 2000; Sokolowski and Corbin 2012; Tovote et al. 2015; Furlong et al. 2016). Although some of the aspects of this complex response to stressors are relatively well known (McMullan and Lumb 2006), the way PAG coordinates some complex motor responses, such as freezing behavior (Roelofs et al. 2010; Roelofs 2017), is still subject of debate.

Anatomical connectivity between PAG with the cerebellum has been subject of interest in the past decades and has been investigated by means of tract-tracing techniques (Chan-Palay 1977; Dietrichs 1983).

Animal studies demonstrated that PAG and cerebellum are connected both directly and indirectly (Watson et al. 2016). Connections joining the cerebellar cortex and nuclei with PAG were first described in monkeys (Chan-Palay 1977). A few years later, a direct connection between PAG and some cerebellar sub-regions was demonstrated using fiber tracers in cats (Dietrichs 1983) and, more recently, in rabbits, between PAG and flocculus folio P (Nisimaru et al. 2013). In addition, neurophysiological 
findings of a strong coupling between PAG and cerebellar functions have also been provided in rats (Koutsikou et al. 2014).

According to these evidences, PAG may modulate cerebellar activity via three distinct, either direct or indirect, ways: (1) by controlling sensory afferent spino-cerebellar projections; (2) by modulating the output response of cerebellar nuclei; (3) by regulating spinal reflex circuits (Cerminara et al. 2009; Koutsikou et al. 2014, 2015, 2017).

In humans, the development of novel magnetic resonance imaging (MRI) sequences and signal modeling techniques has provided important contributions to the study of the functional neuroanatomy of PAG (Menant et al. 2016). In this regard, functional MRI (fMRI) studies demonstrated high statistical dependencies between PAG and cerebellum both in healthy (Kong et al. 2010; Coulombe et al. 2016; Faull and Pattinson 2017) and pathological conditions (Case et al. 2017).

On the other hand, diffusion-weighted imaging (DWI) and tractography represent powerful tools to trace structural connections non-invasively and in vivo (Cacciola et al. 2016, 2017a, c, d, 2018, 2019; Milardi et al. 2016a, b, 2017; Arrigo et al. 2018; Calamuneri et al. 2018), by estimating diffusion properties of magnetically labeled water molecules along myelinated axons (Basser et al. 1994; Henderson 2012). Several tractography studies explored the structural connectivity of PAG in humans (Sillery et al. 2005; Hadjipavlou et al. 2006; Owen et al. 2007, 2008; Ezra et al. 2015), though only a few characterized either direct or indirect pathways between the PAG and cerebellum (Sillery et al. 2005; Hadjipavlou et al. 2006; Owen et al. 2008).

In particular, Sillery and colleagues (2005) found direct connections between PAG and cerebellum using probabilistic tractography with $1.5 \mathrm{~T}$ MRI on seven healthy subjects. Similar connections were described by Owen and coworkers (2008) in two out of four patients with deep brain stimulation (DBS) electrodes implanted in PAG for treating chronic pain.

However, to the best of our knowledge, none of these studies precisely characterized the topographical distributions of connections between the PAG and the cerebellar subregions. Therefore, aim of the present study was the systematic investigation and characterization of the structural connections between PAG and both the cerebellar cortex and nuclei. We employed multi-shell, high-angular resolution diffusion MRI (HARDI) data of 100 healthy subjects from the WU-Minn Human Connectome Project (HCP) repository combined with constrained spherical deconvolution (CSD) signal modeling. Herein, we provide comprehensive qualitative and quantitative descriptions of the connectivity patterns between the PAG and cerebellum.

\section{Materials and methods}

\section{Subjects and data acquisition}

High-quality structural and diffusion MRI data from the HCP repository have been employed. We obtained data for 100 healthy subjects (males $=46$, females $=54$ age range 22-36 years). Data were acquired by the Washington University, University of Minnesota, and Oxford University (WU-Minn) HCP Consortium (Van Essen et al. 2013). All the HCP subjects were scanned using a Siemens 3T Skyra scanner previously modified with a Siemens SC72 gradient coil and stronger gradient power supply with maximum gradient amplitude (Gmax) of $100 \mathrm{mT} / \mathrm{m}$ (initially $70 \mathrm{mT} / \mathrm{m}$ and $84 \mathrm{mT} / \mathrm{m}$ in the pilot phase), with the aim of improving diffusion imaging (Van Essen et al. 2013). The structural scans included T1-weighted acquisitions with the following parameters: $\mathrm{TE}=2.14 \mathrm{~ms}, \mathrm{TR}=2400 \mathrm{~ms}$, voxel size $=0.7 \mathrm{~mm}$. (Uğurbil et al. 2013). Diffusionweighted images were acquired using a single-shot 2D spin-echo multiband echo planar imaging (EPI) sequence and equally distributed over three shells ( $b$-values of $1000 \mathrm{~s} / \mathrm{mm}^{2}, 2000 \mathrm{~s} / \mathrm{mm}^{2}$, and $3000 \mathrm{~s} / \mathrm{mm}^{2}$ ), with isotropic spatial resolution of $1.25 \mathrm{~mm}$ (Sotiropoulos et al. 2013).

Data employed in this study were downloaded in the minimally pre-processed form consisting of: normalization of $b_{0}$ image intensity across runs, registration of $b_{0}$ images to $\mathrm{T} 1 \mathrm{w}$ acquisition and other corrections, such as those for EPI susceptibility, eddy-current-induced distortions, gradient nonlinearities and subject motion (Glasser et al. 2013).

\section{MRI post-processing}

Both structural and diffusion images were post-processed to perform tractography. Briefly, structural images underwent brain extraction (Smith 2002) and cortical and subcortical segmentation (Patenaude et al. 2011; Zhang et al. 2001) using BET, FAST and FIRST tools in FSL (Smith et al. 2004). The obtained masks were visually inspected and, if needed, modified by a trained neuroanatomist. A five-tissue segmented image was then obtained and used to run multi-shell multi-tissue CSD (MSMT-CSD), an improvement of CSD signal modelling technique, in which fiber orientation distribution function (fODF) is estimated directly from deconvolution of diffusion-weighted signal with a reference single-fiber response function (Tournier et al. 2007, 2008). The MSMT-CSD modelling technique represents a variant designed to support multi-shell data and to overcome classical CSD limitations when it comes to estimate fODF in the presence of tissue-type 
heterogeneity (Jeurissen et al. 2014). Estimation of fODF and tractography were performed using the MRtrix software (http://www.mrtrix.org) (Tournier et al. 2012).

\section{Region of interest (ROI) segmentation}

To obtain useful ROIs for tractography (see paragraph below), both automated and semi-automated segmentation methods were used. The steps followed to obtain ROIs are listed in the following pipeline.

1. The ROIs were warped from MNI space to subject native space for each of our 100 subjects as follows: FSL's FLIRT tool was applied to obtain a liner registration, and then a nonlinear registration (FSL's FNIRT tool) was obtained from the affine registration of the previous step. The non-linear transformation was used to warp ROIs from MNI space to subject space.

2. The ROI of the PAG was obtained from the Keuken and Forstmann's 7T atlas that provides ROIs obtained from high-resolution MP2RAGE and FLASH scans warped in MNI space (Keuken and Forstmann 2015) available at https://www.nitrc.org/projects/atag/. Once the ROI was resliced in the MNI space, a probability threshold of $50 \%$ was set employing the FSL's command fslmaths.

3. Cerebellar ROIs were obtained using SUIT Atlas (http:// www.diedrichsenlab.org/imaging/suit.html), a free probabilistic atlas of the human cerebellum in a dedicated space (SUIT space) designed to improve the alignment of infratentorial structures in respect to conventional MNI space (Diedrichsen et al. 2009, 2011; Diedrichsen 2006). We ran the segmentation pipeline for each subject using SUIT toolbox on SPM12 (Ashburner and Friston 2011) and obtained a large cerebellar ROI including cerebellar cortex and nuclei, from which we extracted all the cerebellar lobular and nuclear ROIs (Fig. 1).

4. The cerebellum was parcellated in 34 regions of interest (six nuclei and 28 cerebellar cortex sub-regions includ- ing lobules and vermis) using SUIT (Diedrichsen et al. 2009). The whole PAG was considered as a median structure whilst the cerebellar cortex parcellation provided 12 subregions for each cerebellar hemisphere (Crus I, Crus II, Lobules I-IV, Lobule V, Lobule VI, Lobule VIIb, Lobule VIIIa, Lobule VIIIb, Lobule IX, Lobule $\mathrm{X}$, dentate nucleus, interposed nucleus, fastigial nucleus), whereas the vermis was further subdivided in eight lobules (Vermis Crus I, Vermis Crus II, Vermis VI, Vermis VIIb, Vermis VIIIa, Vermis VIIIb, Vermis IX, Vermis X) (Fig. 1).

5. The cerebral grey matter (GM) previously obtained from FAST was also used as exclusion mask to filter out tracts that were not directed to cerebellar or brainstem grey matter, thus avoiding erroneous assignments (Verstynen et al. 2011, see below). The obtained grey matter mask was manually edited and then resliced into each subject's native space using FLIRT tool on FSL.

6. Finally, since the high spatial proximity between PAG and the quadrigeminal plate (inferior and superior colliculi) could generate spurious tracts, e.g. from tectocerebellar pathways, we manually defined the quadrigeminal plate as region of avoidance (ROA). This ROA was outlined by a trained neuroanatomist on the MNI152 template and then warped it in subject's native space using FLIRT tool on FSL.

All the aforementioned ROIs and ROAs were visually inspected and, if needed, manually modified for each subject by one of the authors.

\section{Tractography}

Tractography was performed in the native space of each subject using the following pipeline: first, we reconstructed 1 million tracts using the PAG ROI as seed region, the large cerebellar ROI as inclusion mask (MRtrix's -include option), the brain GM and quadrigeminal plate ROIs as
Fig. 1 Sagittal and coronal sections of the MNI152 template (voxel size $0.5 \mathrm{~mm}$ ). a ROI of the periaqueductal grey taken from the probabilistic atlas of the basal ganglia by Keuken and collegues was overlaid on the mid-sagittal plane. b Coronal view showing a colored scale of the vermal and hemispheric subregions provided by SUIT atlas

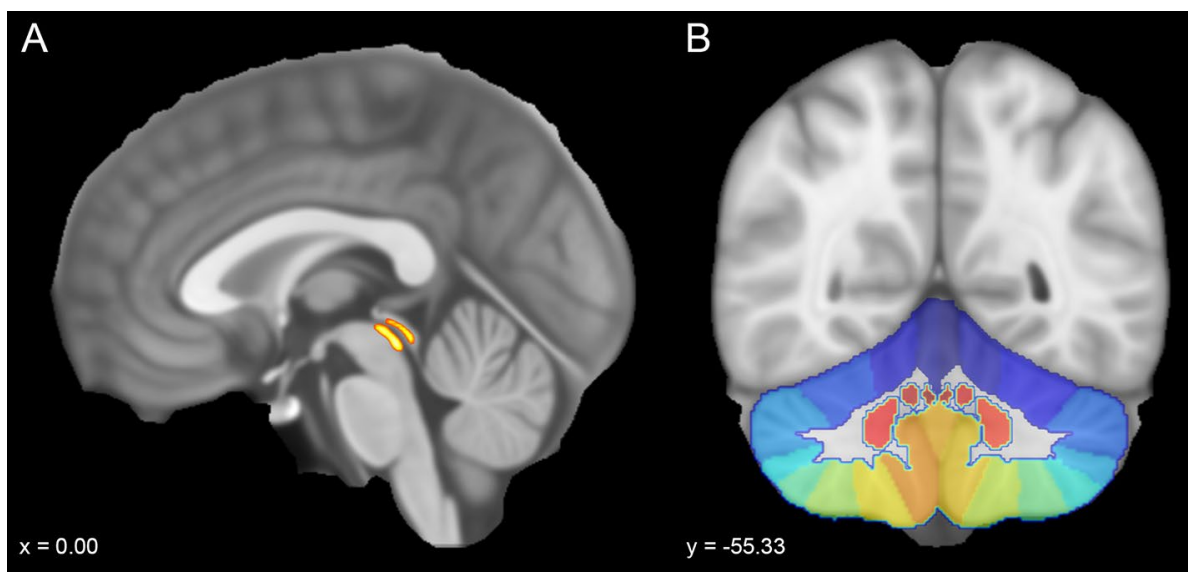


exclusion masks (-exclude option) and IFod2 as fibertracking algorithm (Tournier et al. 2012).

In our study, spherical harmonic degree was fixed equal to six to obtain robustness to noise. During tractography, tracking was stopped in one of the following conditions: step size $=0.2 \mathrm{~mm}$, maximum angle $=10^{\circ}$, minimal fODF amplitude $=0.15$. This is a more conservative choice with respect to usual standards, since we preferred to underestimate fiber bundles to have more consistent reconstructions (Cacciola et al. 2017b; Descoteaux et al. 2009; Rizzo et al. 2018; Tournier et al. 2011). Once obtained 1 million streamlines between PAG and cerebellar ROI, tracts were "filtered out" using each single cerebellar lobular and nuclear ROI as inclusion mask and all the others as exclusion masks, and thus extracting single connections of interest between each cerebellar target region and PAG. It is worthy to note that we extensively used appropriate regions of avoidance (-exclude option) for an accurate extraction of streamlines of interest, and to avoid erroneous tract assignation (Verstynen et al. 2011).

\section{Connectivity analysis}

Connectivity measures were obtained using in-house scripts built with MATLAB software package (http:// www.mathworks.com), release 2015b. At first, the number of streamlines (NOS) connecting PAG to cerebellar regions was assessed. We defined connectivity density $(\delta)$ of each pathway of interest as the contribution of each target region, respectively, to the total NOS. With some limitations (Smith et al. 2013), such numbers are used as markers of connectivity density, both in healthy and pathological conditions (Behrens and Sporns 2012; Bijttebier et al. 2015; Guo et al. 2016; Zhang et al. 2017).

Since connectivity between seed region and regions of interest (ROI) is subjected to volume biases (Cheng et al. 2012), we extracted seed and target ROI volumes to scale the NOS by the mean volume of the two ROI involving each pathway thus computing a normalized connectivity density not affected from the volume bias $\left(\delta_{\text {NORM }}\right)$. Hence, removing ROI volume contributions, we could estimate connectivity density profiles that are less sensitive to individual volumetric differences.

To summarize the distribution of the connectivity density for each reconstructed pathway, we computed the mean normalized density $\left(\delta_{\text {NORM }}\right)$ and standard deviation (SD) from individual subject profiles.

Furthermore, for each connectivity density measure and for each pathway reconstructed, we assessed the inter-subject variability by means of coefficient of variation (COV), which was defined as the ratio of the SD to the $\delta_{\text {NORM }}$ estimated.
Finally, a lateralization index (LI) (Parker et al. 2005) was calculated for assessing lateralization in the investigated pathways as follows:

LI $=\frac{\text { Left }- \text { Right }}{\text { Left }+ \text { Right }}$.

Positive values of $\mathrm{LI}$ indicate left lateralization ( $\mathrm{LI}>0.1$ ), whereas negative values indicate right lateralization $(\mathrm{LI}<0.1)$. For each pathway, to assess statistically significant lateralization, permutation tests based on a $t$-statistic were performed using the connectivity profiles of each hemisphere gathered from each subject. 50.000 permutations were used to estimate the distribution of the null hypothesis, alpha level was set to 0.05 , and the "tmax" method was adopted to correct the $p$ values of each variable for multiple comparisons (Blair and Karkiski 1993).

\section{Results}

To better summarize our results, we grouped cerebellar subregions following the structural and functional anatomical subdivision of the cerebellum described by Stoodley and Schamamann (2016). Lobules, vermal regions and deep cerebellar nuclei have been attributed to four compartments: (1) anterior cerebellum (Lobules I-IV, V), (2) posterior cerebellum (Lobules and Vermis VI, Crus I, Crus II, VIIb, VIIIa, VIIIb, IX), (3) flocculonodular lobe (Lobule and Vermis X), and (4) deep cerebellar nuclei (dentate nucleus, interposed nucleus and fastigial nucleus).

A first analysis focused on the morphological characterization of the fiber tracts connecting the PAG with the cerebellar structures. The streamlines arising from the PAG ran through the superior cerebellar peduncle and follow the arbor vitae of the cerebellum reaching nuclei, vermal regions and lobules. Connectivity patterns joining the PAG, respectively, with the deep cerebellar nuclei (Fig. 2), the entire vermis (Fig. 3) and lobules (Fig. 4) have been successfully reconstructed in all subjects.

A second analysis was finalized to assess quantitative structural connectivity by calculating the $\delta_{\text {NORM }}$ from connectivity data as described in the Connectivity analysis section. Consistent $\delta_{\text {NORM }}$ was found between PAG and all the cerebellar subregions across hemispheres, vermis and deep nuclei here considered. However, to provide more robust results, a probabilistic threshold $\left(\delta_{\mathrm{NORM}}>1 \%\right)$ has been applied to normalized tractograms to remove false-positive results (Rubinov and Sporns 2010). However, choosing a proper cut-off value remains quite empirical and still constitutes matter of debate (van Wijk et al. 2010).

Thus, only connections exceeding the probabilistic threshold $\delta_{\text {NORM }}>1 \%$ of the whole PAG-cerebellum tracts 


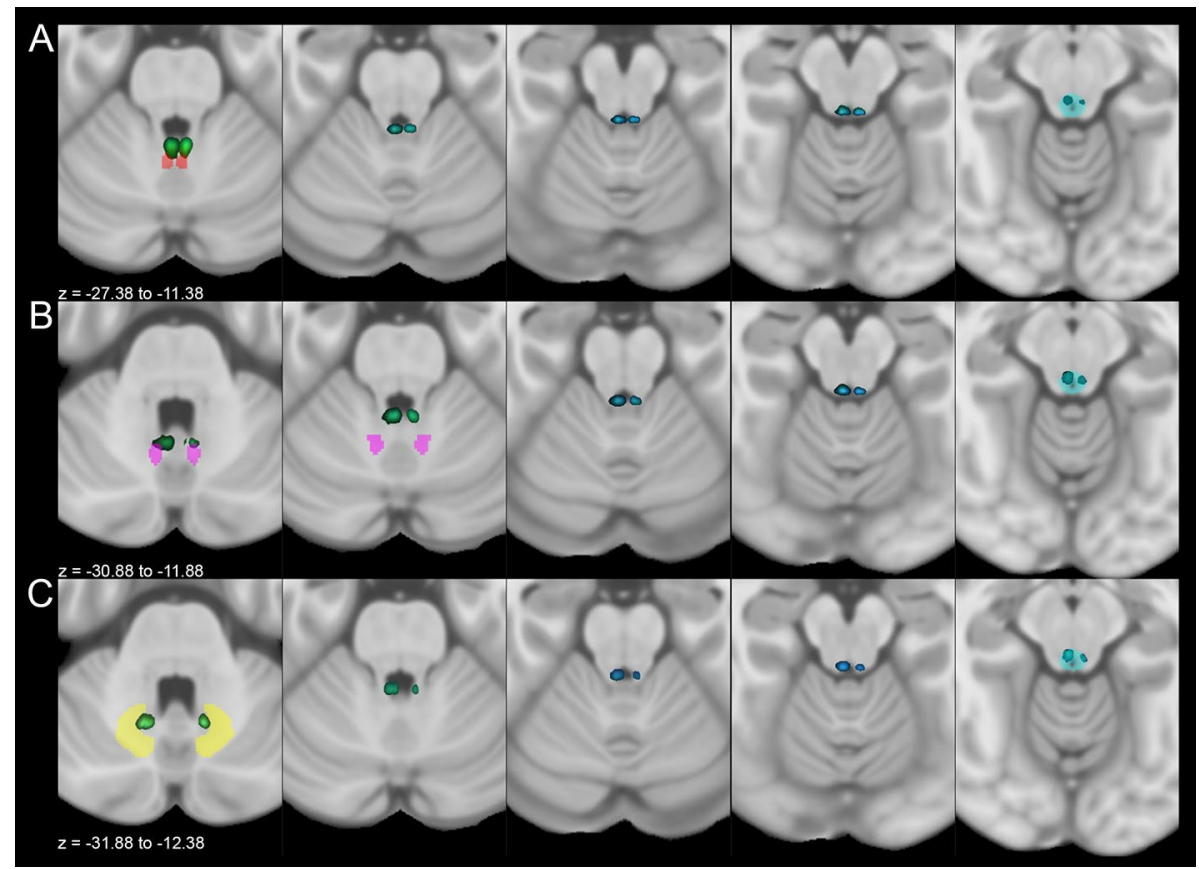

Fig. 2 Average track density maps showing connections between cerebellar nuclei and periaqueductal grey mapped in directionally encoded color space (DEC) and superimposed to the MNI152 template. a Axial slices showing the course of tracts joining fastigial nucleus (red) and periaqueductal grey (cyan). The tracts leave the fastigial nucleus, pass through the superior cerebellar peduncle and reach the periaqueductal grey in the mesencephalon, sparing the superior colliculi. b Axial slices showing the course of tracts between interposed nucleus (pink) and periaqueductal grey (cyan). Tracts reach the mesencephalic periaqueductal grey via the superior cerebellar peduncle sparing the superior colliculi. c Axial slices representing the course of connections between dentate nucleus (yellow) and periaqueductal grey (cyan). The tracts leave the dentate nucleus, run through superior cerebellar peduncles and reach the periaqueductal grey avoiding superior colliculi
Fig. 3 Average track density maps showing tracts connecting cerebellar vermal regions and periaqueductal grey mapped in directionally encoded color space (DEC) and superimposed to the MNI152 template. a Course of tracts connecting the Vermal lobule IX (violet) and the periaqueductal grey (cyan). b Connections between Vermal lobule VIIIa (green) and periaqueductal grey (cyan). c Tracts between Vermal lobule VI (brown) and periaqueductal grey (cyan). d Course of tracts joining Vermal lobule X (pink) to periaqueductal grey (cyan). e Connections between Vermal lobule VIIIb (blue) and periaqueductal grey (cyan)

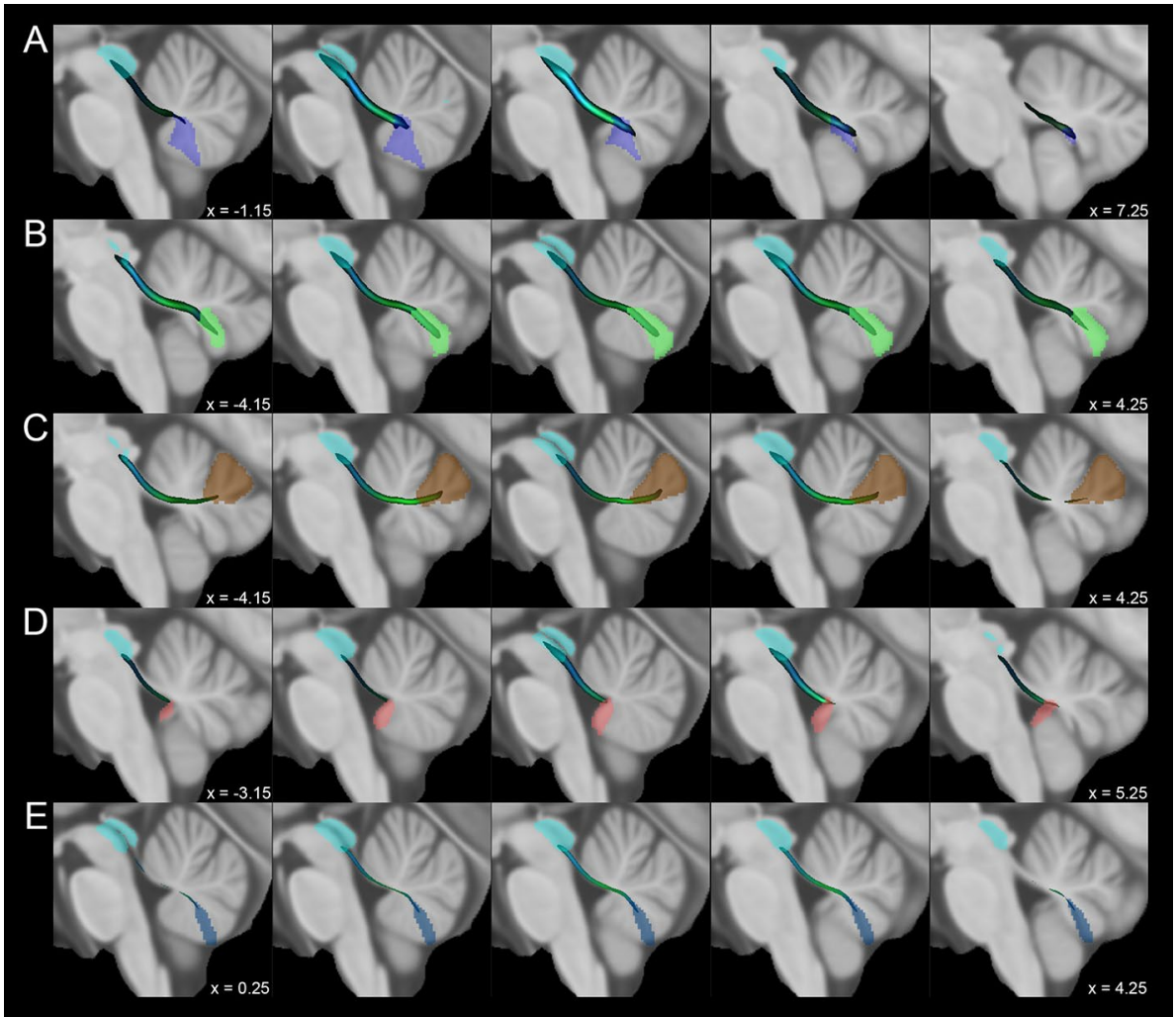


Fig. 4 Average track density maps showing tracts connecting cerebellar hemispheric regions to periaqueductal grey mapped in directionally encoded color space (DEC) and superimposed to the MNI152 template. Sagittal views depicting tracts connecting a the left hemispheric Lobule IX (purple) and b the right hemispheric Lobule IX (orange) with the periaqueductal grey (cyan)

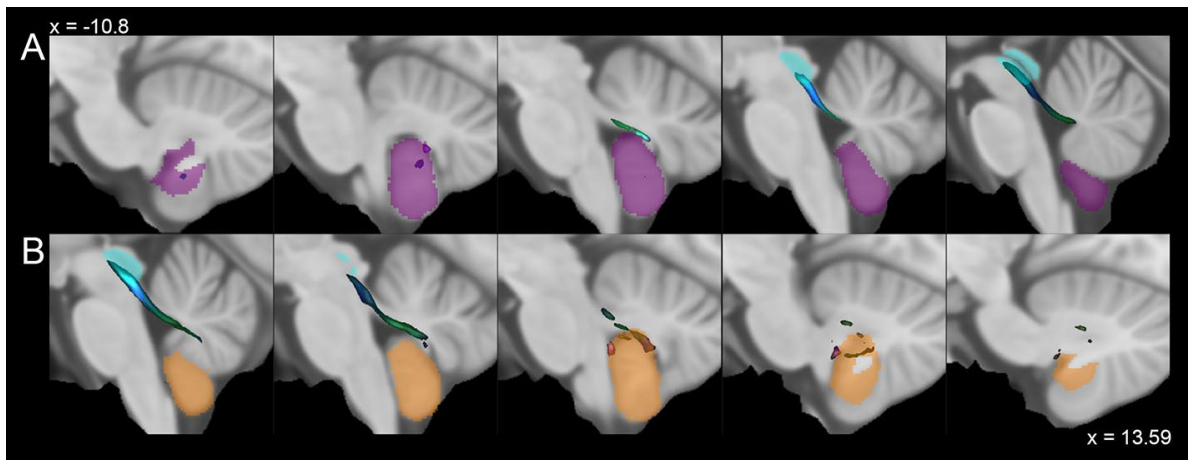

were considered as true positives and will be object of discussion.

Robust connectivity patterns have been demonstrated between the PAG and cerebellar nuclei: the fastigial nucleus resulted to be the most connected (right: $17.2 \pm 8.4 \%$; left: $10.5 \pm 5.4 \%$ ), followed by the interposed nucleus (right: $10.7 \pm 6.1 \%$; left: $4.3 \pm 3.6 \%$ ) and the dentate nucleus (right: $4.5 \pm 3.3 \%$; left: $1.8 \pm 1.6 \%$ ) (Fig. 2, Table 1).

The structures of the posterior compartment which showed consistent connectivity patterns with the PAG were the Vermis IX $(12.4 \pm 6.0 \%)$, Vermis VIIIa $(9.9 \pm 5.4 \%)$, Lobule IX (right: $9.2 \pm 4.1 \%$; left: $5.8 \% \pm 3.0 \%$ ), Vermis VI $(5.1 \% \pm 3.5 \%)$ and Vermis VIIIb $(1.7 \pm 1.2 \%)$, while Lobule VI, VIIIa, VIIIb, vermal and lobular Crus I, Crus II and VIIb showed an average $\delta_{\text {NORM }}<1 \%$. Connections between the PAG and flocculonodular lobe were also present with robust connections with the Vermis $\mathrm{X}(4.5 \pm 3.1 \%)$ and weaker connectivity with Lobule $\mathrm{X}(<1 \%)$ (Figs. 3 and 4$)$.

The normalized connectivity density profiles are summarized in Table 1.

We also investigated the consistency of density percentages estimated from our subjects by looking at the COV. The most consistent results were obtained for the connections between the PAG and the right Lobule IX $(\mathrm{COV}=0.44)$, the Vermis IX $(\mathrm{COV}=0.48)$ and the right fastigial nucleus $(\mathrm{COV}=0.49)$, whereas the highest variability between subjects was observed for the right dentate nucleus $(\mathrm{COV}=0.72)$, the left interposed nucleus $(\mathrm{COV}=0.84)$ and the left dentate nucleus $(\mathrm{COV}=0.89)$.

It is worthy to note that highest COVs (one or above) often correspond to lowest values of mean $\delta_{\text {NORM }}$, mostly under the fixed threshold of $1 \%$. This indicates that less connected regions are, at the same time, the most variable among subjects suggesting that the application of the aforementioned threshold could help to distinguish reliable from unreliable connections (Roberts et al. 2017).

A third analysis was carried out to assess the connectivity between PAG and each cerebellar compartment. The $\delta_{\text {NORM }}$ percentage revealed a prominent connectivity to nuclear region $(49.10 \pm 12.78 \%)$, followed by posterior
$(45.35 \pm 10.24 \%)$, the flocculonodular $(5.16 \pm 3.23 \%)$ and anterior lobes $(0.38 \pm 0.30 \%)$.

Finally, the lateralization analysis, performed to assess differences between the connectivity profiles of PAG with the left and right cerebellar lobules and nuclei, revealed no significant side-to-side variations $(p>0.05)$.

\section{Discussion}

Our study aimed at providing new insights on the structural connectivity between the PAG and cerebellum performing MSMT-CSD tractography on high-resolution data from the WU-Minn HCP database. We observed that the PAG is highly connected with both the cerebellar cortex and deep cerebellar nuclei. To better summarize and discuss our findings, we will follow the structural and functional anatomical classification of the cerebellum proposed by Stoodley and Schmahmann (2009, 2010, 2016) (Fig. 5). The connectivity density profiles between PAG and cerebellar structures will be discussed following the structural classification, considering the existing literature regarding PAG-cerebellar connectivity (Table 2). The possible functional significance of the reconstructed connectivity patterns will be discussed in the last paragraph of the discussion.

\section{Deep cerebellar nuclei}

Our connectivity analysis showed the highest strength for the connectivity patterns linking the PAG and the three deep cerebellar nuclei. While similar connections were reported in animals (Chan-Palay 1977; Koutsikou et al. 2015; Moers-Hornikx et al. 2011), to the best of our knowledge, our study represents the first evidence of the possible existence of the human analogues of these pathways in humans. The most connected nucleus to the PAG was the Fastigial nucleus, followed by the interposed and dentate nuclei (Fig. 2, Table 1). In rats, DBS of the dorsolateral column of PAG induces panic attacks and deactivates the deep cerebellar nuclei (Moers-Hornikx et al. 
Table 1 Connectivity density (\%) between the PAG and cerebellar structures

\begin{tabular}{|c|c|c|c|}
\hline \multicolumn{4}{|c|}{ Normalized connectivity density } \\
\hline Structure & Mean & SD & $\mathrm{COV}$ \\
\hline Right fastigial nucleus & 17.24 & 8.41 & 0.49 \\
\hline Vermis IX & 12.43 & 6.02 & 0.48 \\
\hline Right interposed nucleus & 10.75 & 6.09 & 0.57 \\
\hline Left fastigial nucleus & 10.47 & 5.44 & 0.52 \\
\hline Vermis VIIIa & 9.90 & 5.38 & 0.54 \\
\hline Right Lobule IX & 9.20 & 4.07 & 0.44 \\
\hline Left Lobule IX & 5.81 & 2.97 & 0.51 \\
\hline Vermis VI & 5.07 & 3.52 & 0.69 \\
\hline Right dentate nucleus & 4.56 & 3.27 & 0.72 \\
\hline Vermis X & 4.52 & 3.14 & 0.69 \\
\hline Left interposed nucleus & 4.29 & 3.58 & 0.84 \\
\hline Left dentate nucleus & 1.81 & 1.60 & $\mathbf{0 . 8 9}$ \\
\hline Vermis VIIIb & 1.72 & 1.18 & 0.69 \\
\hline Right Crus II & 0.51 & 0.58 & 1.12 \\
\hline Right Lobule X & 0.43 & 0.70 & 1.62 \\
\hline Left Lobule X & 0.21 & 0.30 & 1.39 \\
\hline Left Crus II & 0.18 & 0.20 & 1.10 \\
\hline Right Lobules I-IV & 0.15 & 0.10 & 0.66 \\
\hline Right Lobule VIIIa & 0.13 & 0.14 & 1.07 \\
\hline Left Lobule V & 0.09 & 0.20 & 2.25 \\
\hline Right Lobule V & 0.08 & 0.20 & 2.54 \\
\hline Right Lobule VIIb & 0.07 & 0.09 & 1.31 \\
\hline Right Lobule VIIIb & 0.07 & 0.13 & 1.89 \\
\hline Left Lobule VIIIb & 0.07 & 0.08 & 1.20 \\
\hline Left Lobules I-IV & 0.06 & 0.05 & 0.75 \\
\hline Left Lobule VIIIa & 0.05 & 0.06 & 1.03 \\
\hline Right Crus I & 0.04 & 0.06 & 1.63 \\
\hline Left Lobule VIIb & 0.04 & 0.04 & 1.04 \\
\hline Vermis VIIb & 0.02 & 0.03 & 1.44 \\
\hline Right Lobule VI & 0.01 & 0.03 & 2.55 \\
\hline Left Crus I & 0.01 & 0.02 & 1.25 \\
\hline Vermis Crus II & 0.01 & 0.02 & 2.27 \\
\hline Left Lobule VI & 0.01 & 0.01 & 1.96 \\
\hline Vermis Crus I & 0.00 & 0.00 & 0.00 \\
\hline
\end{tabular}

Connections exceeding the probabilistic threshold $\delta_{\mathrm{NORM}}>1 \%$ of the whole PAG-cerebellum tracts are reported in bold

$S D$ standard deviation, $C O V$ coefficient of variation, $P A G$ periaqueductal gray

2011), whereas stimulation of the ventrolateral column of PAG induces Fos expression in fastigial (medial) nucleus (Koutsikou et al. 2015). It is worth to note that the majority of tracts between PAG and cerebellum reached the fastigial nucleus that, in addition to its well-known motor and oculomotor functions, is also involved in regulating complex vegetative responses such as cardiovascular tone, micturition, defecation, gastro-intestinal peristalsis and respiratory rate (Zhang et al. 2017) and is connected with limbic regions (Blatt et al. 2013). Moreover, the interposed nucleus, which retrieved high connectivity density values, also appears to play a role in fear conditioning (Sacchetti et al. 2002).

\section{Posterior cerebellum}

Lower connectivity density profiles were observed between the PAG and the posterior lobe of the cerebellum. Interestingly, the highest values of connectivity for the regions belonging to posterior lobe were obtained for the uvula (Vermal lobule IX) and vermal pyramis (Vermal lobule VIIIa and VIIIb). The uvula is a well-known component of the vestibular cerebellum and receives afferents from vestibular receptors (Barmack 2003), exerting a well-recognized role in ocular movements (Voogd et al. 2012) and in postural adjustments via the regulation of the vestibulospinal system (McCall et al. 2017). On the other hand, the vermal pyramis is a component of the motor cerebellum: Vermal lobule VIII and the hemispheric Lobules VIII and IX are somatotopically organized constituting the posterior homunculus of the human cerebellum (Snider and Eldred 1951; Grodd et al. 2001). In rats, the electrical stimulation of the ventrolateral column of PAG leads to the activation of the vermal pyramis, eliciting fear-related freezing behavior, likely by influencing spinal descending neurons (Koutsikou et al. 2014). Finally, high-connectivity values were also found for Vermal lobule $\mathrm{VI}$, a posterior vermis region that is part of the oculomotor vermis (Kheradmand and Zee 2011), but that also plays a role in the regulation of autonomic functions (Strata 2015) and in conditioned fear acquisition and retention (Sacchetti et al. 2004, 2007, 2009).

\section{Flocculonodular lobe}

Finally, our probabilistic tractography study revealed connectivity patterns between the PAG and the flocculonodular lobe. Interestingly, the flocculonodular lobe reported the lowest connectivity values compared to the other lobes. It is worth to note that connections between PAG and flocculus folio $\mathrm{P}$ have been previously described as part of an hypothalamo-PAG-cerebellar pathway in rabbits (Nisimaru et al. 2013). As it is well known, together with uvula (Vermal lobule IX), lingula (Vermal lobules I-II) and the fastigial nucleus, the flocculonodular lobe is a key structure in the so-called paleocerebellum or vestibulocerebellum, involved in the regulation of ocular movements and posture by integrating vestibular afferences (Barmack 2003; McCall et al. 2017; Stoodley and Schmahmann 2016; Voogd et al. 2012; Zhang et al. 2017). 
Fig. 5 Multiple axial sections showing cerebellum lobules grouped as functional compartments: sensorimotor (red), cognitive/affective (blue), vestibular (yellow). Deep cerebellar nuclei have been labeled as follows: dentate in purple, interposed in cyan and fastigial in green

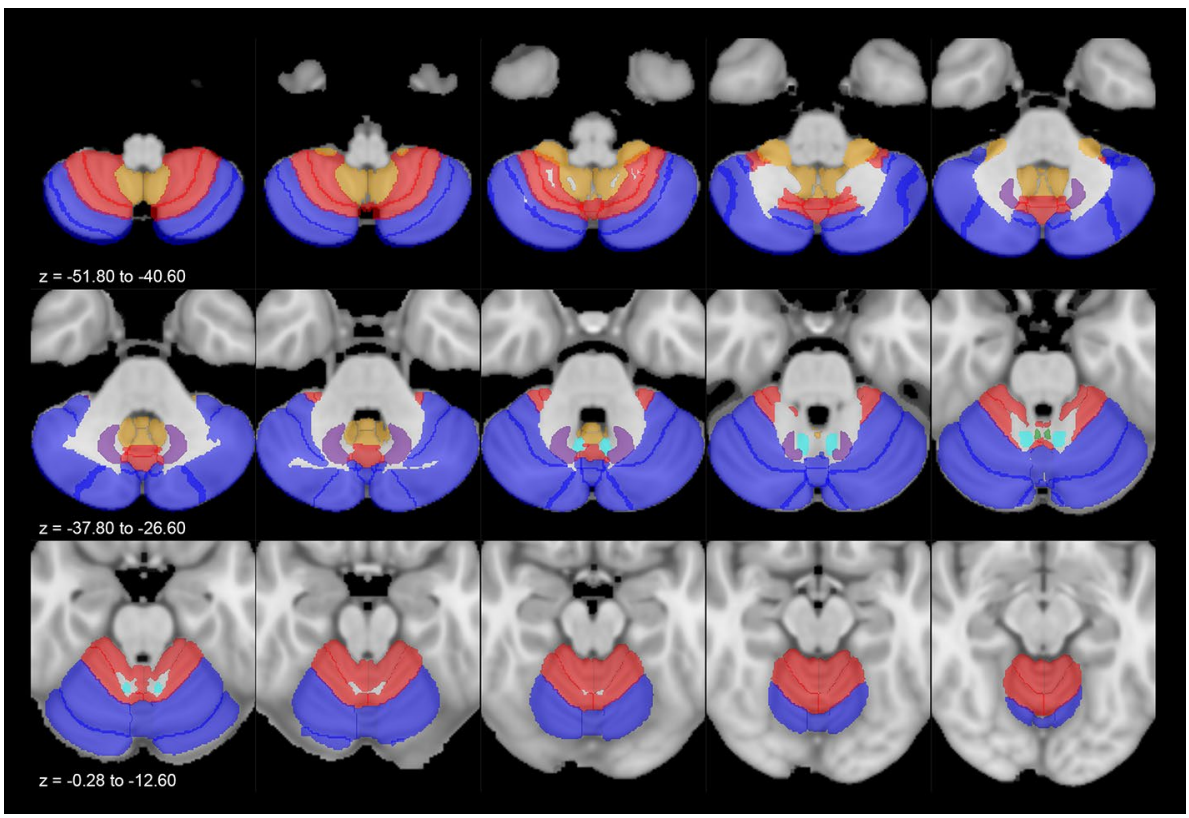

Table 2 Evidences for the cerebellar-periaqueductal gray connectivity in animals and humans according to the existing literature

\begin{tabular}{|c|c|c|c|}
\hline Authors (years) & Species & Method & Findings \\
\hline Chan-Palay (1977) & Monkeys & Fiber tracing & $\begin{array}{l}\text { Indirect PAG-olivo-cerebellar connections; direct fibers } \\
\text { from dentate nucleus }\end{array}$ \\
\hline Dietrichs (1983) & Cats & Fiber tracing & $\begin{array}{l}\text { Direct connections from PAG to lobulus simplex, Crus I, } \\
\text { Crus II, paramedian lobule and posterior lobule vermis }\end{array}$ \\
\hline Teune et al. (2000) & Rats & Fiber tracing & Direct connections fibers from all cerebellar nuclei to PAG \\
\hline Sillery et al. (2005) & Humans & Diffusion tensor imaging & Direct PAG-cerebellar connections \\
\hline Owen et al. (2008) & Humans & Diffusion tensor imaging & $\begin{array}{l}\text { Direct PAG-cerebellar connections based on pre-operative } \\
\text { DTI for chronic pain }\end{array}$ \\
\hline Cerminara et al. (2009) & Rats & Electrophysiology & Connections with paramedian lobule and copula pyramidis \\
\hline Kong et al. (2010) & Humans & Resting-state functional MRI & $\begin{array}{l}\text { High functional PAG-cerebellum connectivity (unspecified } \\
\text { regions) }\end{array}$ \\
\hline Moers-Hornikx et al. (2011) & Rats & Immunohistochemistry & $\begin{array}{l}\text { Deactivation of deep cerebellar nuclei after PAG stimula- } \\
\text { tion }\end{array}$ \\
\hline Nisimaru et al. (2013) & Rabbits & Electrophysiology, immunohistochemistry & $\begin{array}{l}\text { Hypothalamo-PAG-cerebellar neurons ending in flocculus } \\
\text { folio P }\end{array}$ \\
\hline Watson et al. (2013) & Rats & Electrophysiology & Indirect PAG-olivo-cerebellar connections \\
\hline Koutsikou et al. (2014) & Rats & Electrophysiology & Connections with Vermis VIII and pyramis \\
\hline Koutsikou et al. (2015) & Rats & Electrophysiology, immunohistochemistry & Connections with medial cerebellar nucleus \\
\hline Coulombe et al. (2016) & Humans & Resting-state functional MRI & High PAG-cerebellum functional connectivity \\
\hline Case et al. (2017) & Humans & Resting-state functional MRI & $\begin{array}{l}\text { Higher functional PAG-cerebellum connectivity in sickle- } \\
\text { cell disease patients vs controls }\end{array}$ \\
\hline Faull and pattinson (2017) & Humans & Resting-state functional MRI & Functional connectivity with Lobules I-IV, V, VI, Crus I \\
\hline
\end{tabular}

\section{Anatomo-functional considerations}

Reactions to external threatening stimuli, such as fear and anxiety, require a complex regulation that involves the integration of cognitive, vegetative and motor responses. The PAG represents the main neural hub involved in top-down control of these responses to stressful or painful external stimuli.

One of such possible responses is the so-called freezing behavior, largely described in animals: the animal acquires a crouched posture (Blanchard and Blanchard 1969), increases its muscular tone, remains still and reduces vegetative 
parameters such as heart rate (Carrive 2000; Fanselow 1980, 1994; Kozlowska et al. 2015). As previously outlined, this response depends on PAG activation and is related to PAG-cerebellum interactions (Koutsikou et al. 2014). More recently, a similar response was described in humans (Hagenaars et al. 2014a, b; Roelofs 2017). In particular, reduced body sway and heart rate was observed in human individuals after the presentation of visual threatening stimuli such as emotionally significant pictures or films (Roelofs et al. 2010; Hagenaars et al. 2014a). However, the neuroanatomical substrates of this kind of response are still not clearly characterized in humans. Converging evidences from in vivo neuroimaging studies suggest that freezing behavior depends on prefrontal-amygdala-PAG functional connectivity (Mobbs et al. 2010; Hermans et al. 2013), but information is still lacking about the interface between the PAG and the motor system, that appear to be necessary to elicit such a complex and immediate postural response. Recently, PAG functional connectivity was evaluated during breathlessness, which is a multidimensional biopsychological condition that is associated with a strong affective component and feeling of fear and anxiety that could, in turn, lead to defensive responses such as freezing (Lansing et al. 2009; Herigstad et al. 2011; Hayen et al. 2013). A resting-state fMRI study found strong functional connectivity between the cerebellum and the ventrolateral column of PAG, in line with the present study and with previous animal findings. Interestingly, the same study performed task-related functional connectivity using psychophysiological interaction analysis in both breathlessness and breathlessness anticipation conditions, revealing that the strength of functional connectivity between the cerebellum and PAG is negatively correlated with the perceived intensity of breathlessness (Faull and Pattinson 2017). These data, thus, suggest an important role for the cerebellar-PAG interplay in coping responses to threatening stimuli, demonstrating how its "breakdown" could lead to a worse response to dangerous situations.

In this view, and in line with previous findings in animals, our results could be seen as a possible anatomical substrate for similar responses in humans. Indeed, we showed that the PAG is highly connected with the deep cerebellar nuclei, and especially with the fastigial and interposed nuclei, which play important roles in both motor and nonmotor vegetative functions such as autonomical regulation (Zhang et al. 2017) and fear conditioning (Sacchetti et al. 2002).

Moreover, robust connectivity density profiles were reported with motion- and posture-related cerebellar regions: the aforementioned deep cerebellar nuclei, vestibulocerebellar regions such as uvula and nodulus (Vermis IX-X), and vermal pyramis (VIIIa and VIIIb). Therefore, our results further reinforce the current idea of the involvement of posterior cerebellar vermis in fear conditioning, acquisition and retention (Sacchetti et al. 2002, 2004, 2007, 2009).
The structural connectivity patterns between the PAG and the aforementioned cerebellar regions could thus be hypothesized as part of a widespread network involved in processing fearful or noxious stimuli. However, these results should be interpreted with care, due to intrinsic limitations of the technique. Nevertheless, as a working hypothesis and trigger for further functional and structural investigations, we may suggest that such connections could represent the direct pathways through which the PAG and the cerebellum can cooperate for orchestrating complex responses to threatening stimuli.

\section{Limitations}

This study is prone to limitations due to some intrinsic weaknesses of the technique which have been recently summarized in a recent review (Maier-Hein et al. 2017). Tractography deals with the axial symmetry of diffusion signal which prevents to distinguish afferent from efferent connections. At the same time, this technique is not able to the detect synapses, thus neglecting the recognition of monosynaptic pathways from polysynaptic ones. Consequently, inferences on the layer of the cerebellar cortex to which reconstructed fibers arrive are not allowed (Chung et al. 2011; Parker et al. 2013).

The diameter of axons is too tiny for MRI voxels; indeed, even at the highest definition, a single voxel contains thousands of axons, making the diffusion signal overestimated in respect to the scale of interest (Jbabdi and Johansen-Berg 2011).

Moreover, results reported in tractography studies are strongly influenced by different ways of modelling diffusion signal and depend on reconstruction parameters. An additional issue is represented by different fiber geometry (crossing, kinking, bending) resulting in very similar intravoxel diffusion signal profiles, being instead different each other (Donahue et al. 2016b). Therefore, we employed a CSD-based signal modelling, together with restrictive reconstruction parameters, to overcome potential reconstruction biases that may be related to other modelling techniques (Dauguet et al. 2007; Descoteaux et al. 2009). Moreover, PAG-cerebellum connections not only have been described in animals via tract tracing techniques, but they have been reported by studies conducted on humans by diffusion tractography and fMRI.

The quantitative estimates of structural tractographicbased connectivity are still an open issue. As previously stated, an MRI voxel covers a multitude of axons; thus, the NOS is the most frequent measure employed to assess the strength of connections. However, although the NOS does not correspond to number of axons neglecting an anatomicwise quantitative analysis (Jbabdi and Johansen-Berg 2011; 
Jones et al. 2013), a positive correlation between diffusion path probabilities and results of tract tracing studies has been recently demonstrated, thus validating the use of tractography-derived quantitative measures (Donahue et al. 2016a).

As it is well known, probabilistic tractography could lead to "false-positive" results and could thus overestimate quantitative connectivity measures (Jbabdi and Johansen-Berg 2011). Many authors in the field introduce a threshold, in the attempt to limit the effect of spurious tracking in probabilistic tractography (Rubinov and Sporns 2010; Drakesmith et al. 2015; Roberts et al. 2017). Therefore, tracts that do not contribute with a minimum percentage to the total tractogram are excluded. However, the choice of a proper threshold remains rather empirical and still constitutes subject of debate (van Wijk et al. 2010; Qi et al. 2015). Here, we employed a connectivity threshold $>1 \%$ to define tracts which consistently contributed to the total PAG-cerebellar streamlines. However, despite quite conservative and in line with previous studies, the threshold here employed remains arbitrary and should be acknowledged as an intrinsic limitation of the overall approach.

This is particularly important if we consider that several reconstructed tracts with $\delta_{\mathrm{NORM}}<1 \%$ showed a COV $>1$, demonstrating a high variance in the connectivity density of these pathways among subjects.

Recently, Roberts et al. proposed the use of COV as an alternative connectivity measure for distinguishing less reliable from more reliable connections. This new approach would not underestimate long-range connections that usually show lower connectivity strength. In the present study, where only short range connection are taken into account, connectivity patterns with $\delta_{\text {NORM }}<1 \%$ show the highest COVs suggesting that they may less likely have anatomical plausibility (Roberts et al. 2017).

Finally, despite employing high-definition T1-weighted scans at $0.75 \times 0.75 \times 0.75 \mathrm{~mm}$ resolution, we were not able to reach the necessary definition to distinguish the four longitudinal columns of the PAG and thus to characterize the columnar PAG connectivity.

Acknowledgements Data were provided by the Human Connectome Project, WU-Minn Consortium (Principal Investigators: David Van Essen and Kamil Ugurbil; 1U54MH091657) funded by the 16 NIH Institutes and Centers that support the NIH Blueprint for Neuroscience Research; and by the McDonnell Center for Systems Neuroscience at Washington University.

\section{Compliance with ethical standards}

Conflict of interest The authors declare no conflict of interest.

Research involving human participants Data were provided by the Human Connectome Project, WU-Minn Consortium (Principal Investigators: David Van Essen and Kamil Ugurbil; 1U54MH091657) funded by the 16 NIH Institutes and Centers that support the NIH Blueprint for Neuroscience Research; and by the McDonnell Center for Systems Neuroscience at Washington University.

Informed consent All participants signed informed consent document at the day of scan as part of the Human Connectome Project, WUMinn Consortium (Principal Investigators: David Van Essen and Kamil Ugurbil; 1U54MH091657) funded by the 16 NIH Institutes and Centers that support the NIH Blueprint for Neuroscience Research; and by the McDonnell Center for Systems Neuroscience at Washington University.

Open Access This article is distributed under the terms of the Creative Commons Attribution 4.0 International License (http://creativeco mmons.org/licenses/by/4.0/), which permits unrestricted use, distribution, and reproduction in any medium, provided you give appropriate credit to the original author(s) and the source, provide a link to the Creative Commons license, and indicate if changes were made.

\section{References}

Arrigo A, Calamuneri A, Milardi D et al (2018) Claustral structural connectivity and cognitive impairment in drug naïve Parkinson's disease. Brain Imaging Behav. https://doi.org/10.1007/s1168 2-018-9907-z

Ashburner J, Friston KJ (2011) Diffeomorphic registration using geodesic shooting and Gauss-Newton optimisation. Neuroimage 55:954-967. https://doi.org/10.1016/j.neuroimage.2010.12.049

Bandler R, Keay KA, Floyd N, Price J (2000) Central circuits mediating patterned autonomic activity during active vs. passive emotional coping. Brain Res Bull 53:95-104

Barmack NH (2003) Central vestibular system: vestibular nuclei and posterior cerebellum. Brain Res Bull 60:511-541

Basser PJ, Mattiello J, LeBihan D (1994) MR diffusion tensor spectroscopy and imaging. Biophys J 66:259-267. https://doi. org/10.1016/S0006-3495(94)80775-1

Behrens TEJ, Sporns O (2012) Human connectomics. Curr Opin Neurobiol 22:144-153

Bijttebier S, Caeyenberghs K, van den Ameele H et al (2015) The vulnerability to suicidal behavior is associated with reduced connectivity strength. Front Hum Neurosci 9:632. https://doi. org/10.3389/fnhum.2015.00632

Blair CR, Karkiski W (1993) An alternative method for significance testing of waveform difference potentials. Psychophysiology 30:518-524. https://doi.org/10.1111/j.1469-8986.1993.tb02075.x

Blanchard RJ, Blanchard DC (1969) Crouching as an index of fear. J Comp Physiol Psychol 67:370-375. https://doi.org/10.1037/ h0026779

Blatt GJ, Oblak AL, Schmahmann JD (2013) Cerebellar connections with limbic circuits: anatomy and functional implications. In: Manto M, Gruol DL, Schmahmann J, Koibuchi N, Rossipp F (eds) Handbook of the cerebellum and cerebellar disorders, 1st edn. Springer, Netherlands, pp 479-496

Cacciola A, Milardi D, Anastasi GP et al (2016) A direct cortico-nigral pathway as revealed by constrained spherical deconvolution tractography in humans. Front Hum Neurosci 10:374. https://doi. org/10.3389/fnhum.2016.00374

Cacciola A, Calabrò RS, Costa A et al (2017a) Enlarged virchow-robin spaces in a young man: a constrained spherical deconvolution tractography study. Acta Biomed 88:337-351

Cacciola A, Calamuneri A, Milardi D et al (2017b) A connectomic analysis of the human basal ganglia network. Front Neuroanat 11:85. https://doi.org/10.3389/fnana.2017.00085 
Cacciola A, Milardi D, Calamuneri A et al (2017c) Constrained spherical deconvolution tractography reveals cerebello-mammillary connections in humans. Cerebellum 16:483-495. https://doi. org/10.1007/s12311-016-0830-9

Cacciola A, Milardi D, Livrea P et al (2017d) The known and missing links between the cerebellum, basal ganglia, and cerebral cortex. Cerebellum. https://doi.org/10.1007/s12311-017-0850-0

Cacciola A, Milardi D, Anastasi G, Quartarone A (2018) Corticopallidal connectivity: lessons from patients with dystonia. Ann Neurol 84:158. https://doi.org/10.1002/ana.25255

Cacciola A, Milardi D, Bertino S et al (2019) Structural connectivity-based topography of the human globus pallidus: Implications for therapeutic targeting in movement disorders. Mov Disord. https://doi.org/10.1002/mds.27712

Calamuneri A, Arrigo A, Mormina E et al (2018) White matter tissue quantification at low $b$-values within constrained spherical deconvolution framework. Front Neurol 9:716. https://doi. org/10.3389/fneur.2018.00716

Carrive P (1993) The periaqueductal gray and defensive behaviour:functional representation and neuronal organisation. Behav Brain Res 58:27-47

Carrive P (2000) Conditioned fear to environmental context: cardiovascular and behavioral components in the rat. Brain Res 858:440-445. https://doi.org/10.1016/S0006-8993(00)02029-1

Case M, Zhang H, Mundahl J et al (2017) Characterization of functional brain activity and connectivity using EEG and fMRI in patients with sickle cell disease. NeuroImage Clin 14:1-17. https://doi.org/10.1016/j.nicl.2016.12.024

Cerminara NL, Koutsikou S, Lumb BM, Apps R (2009) The periaqueductal grey modulates sensory input to the cerebellum: a role in coping behaviour? Eur J Neurosci 29:2197-2206. https ://doi.org/10.1111/j.1460-9568.2009.06760.x

Chan-Palay V (1977) Cerebellar dentate nucleus: organization, cytology and transmitters. Springer, Heidelberg

Cheng H, Wang Y, Sheng J et al (2012) Characteristics and variability of structural networks derived from diffusion tensor imaging. Neuroimage 61:1153-1164. https://doi.org/10.1016/j. neuroimage.2012.03.036

Chung HW, Chou MC, Chen CY (2011) Principles and limitations of computational algorithms in clinical diffusion tensor MR tractography. Am. J. Neuroradiol. 32:3-13

Coulombe MA, Erpelding N, Kucyi A, Davis KD (2016) Intrinsic functional connectivity of periaqueductal gray subregions in humans. Hum Brain Mapp 37:1514-1530. https://doi. org/10.1002/hbm.23117

Dauguet J, Peled S, Berezovskii V et al (2007) Comparison of fiber tracts derived from in vivo DTI tractography with 3D histological neural tract tracer reconstruction on a macaque brain. Neuroimage 37:530-538. https://doi.org/10.1016/j.neuroimage .2007 .04 .067

Descoteaux M, Deriche R, Knösche TR, Anwander A (2009) Deterministic and probabilistic tractography based on complex fibre orientation distributions. IEEE Trans Med Imaging 28:269286. https://doi.org/10.1109/TMI.2008.2004424

Diedrichsen J (2006) A spatially unbiased atlas template of the human cerebellum. Neuroimage 33:127-138. https://doi. org/10.1016/j.neuroimage.2006.05.056

Diedrichsen J, Balsters JH, Flavell J et al (2009) A probabilistic MR atlas of the human cerebellum. Neuroimage 46:39-46. https:// doi.org/10.1016/j.neuroimage.2009.01.045

Diedrichsen J, Maderwald S, Küper M et al (2011) Imaging the deep cerebellar nuclei: a probabilistic atlas and normalization procedure. Neuroimage 54(3):1786-1794. https://doi.org/10.1016/j. neuroimage.2010.10.035

Dietrichs E (1983) Cerebellar cortical afferents from the periaqueductal grey in the cat. Neurosci Lett 41(1-2):21-26
Donahue CJ, Sotiropoulos SN, Jbabdi S et al (2016a) Using diffusion tractography to predict cortical connection strength and distance: a quantitative comparison with tracers in the monkey. J 2Neurosci 36:6758-6770. https://doi.org/10.1523/JNEUR OSCI.0493-16.2016

Donahue CJ, Sotiropoulos SN, Jbabdi S et al (2016b) Using diffusion tractography to predict cortical connection strength and distance: a quantitative comparison with tracers in the monkey. J Neurosci 36:6758-6770. https://doi.org/10.1523/JNEUR OSCI.0493-16.2016

Drakesmith M, Caeyenberghs K, Dutt A et al (2015) Overcoming the effects of false positives and threshold bias in graph theoretical analyses of neuroimaging data. Neuroimage 118:313-333. https ://doi.org/10.1016/j.neuroimage.2015.05.011

Ezra M, Faull OK, Jbabdi S, Pattinson KTS (2015) Connectivity-based segmentation of the periaqueductal gray matter in human with brainstem optimized diffusion MRI. Hum Brain Mapp 36:34593471. https://doi.org/10.1002/hbm.22855

Fanselow MS (1980) Conditional and unconditional components of post-shock freezing. Pavlov J Biol Sci Off J Pavlov 15:177-182. https://doi.org/10.1007/BF03001163

Fanselow MS (1994) Neural organization of the defensive behavior system responsible for fear. Psychon Bull Rev 1:429-438. https ://doi.org/10.3758/BF03210947

Fanselow MS, Kim JJ, Young SL et al (1991) Differential effects of selective opioid peptide antagonists on the acquisition of Pavlovian fear conditioning. Peptides 12:1033-1037. https://doi. org/10.1016/0196-9781(91)90056-U

Faull OK, Pattinson KTS (2017) The cortical connectivity of the periaqueductal gray and the conditioned response to the threat of breathlessness. Elife 6:e21749. https://doi.org/10.7554/elife .21749

Furlong TM, Richardson R, McNally GP (2016) Habituation and extinction of fear recruit overlapping forebrain structures. Neurobiol Learn Mem 128:7-16. https://doi.org/10.1016/j. nlm.2015.11.013

Glasser MF, Sotiropoulos SN, Wilson JA et al (2013) The minimal preprocessing pipelines for the Human Connectome Project. Neuroimage 80:105-124. https://doi.org/10.1016/j.neuroimage 2013.04.127

Grodd W, Hulsmann E, Lotze M et al (2001) Sensorimotor mapping of the human cerebellum: fMRI evidence of somatotopic organization. Hum Brain Mapp 13:55-73

Guo X, Duan X, Long Z et al (2016) Decreased amygdala functional connectivity in adolescents with autism: a resting-state fMRI study. Psychiatry Res Neuroimaging 257:47-56. https://doi. org/10.1016/j.pscychresns.2016.10.005

Hadjipavlou G, Dunckley P, Behrens TE, Tracey I (2006) Determining anatomical connectivities between cortical and brainstem pain processing regions in humans: a diffusion tensor imaging study in healthy controls. Pain 123:169-178. https://doi.org/10.1016/j. pain.2006.02.027

Hagenaars MA, Oitzl M, Roelofs K (2014a) Updating freeze: aligning animal and human research. Neurosci Biobehav Rev 47:165-176

Hagenaars MA, Roelofs K, Stins JF (2014b) Human freezing in response to affective films. Anxiety Stress Coping 27:27-37. https://doi.org/10.1080/10615806.2013.809420

Hayen A, Herigstad M, Pattinson KTS (2013) Understanding dyspnea as a complex individual experience. Maturitas 76:45-50

Henderson JM (2012) "Connectomic surgery": diffusion tensor imaging (DTI) tractography as a targeting modality for surgical modulation of neural networks. Front Integr Neurosci 6:15. https://doi. org/10.3389/fnint.2012.00015

Herigstad M, Hayen A, Wiech K, Pattinson KTS (2011) Dyspnoea and the brain. Respir Med 105:809-817. https://doi.org/10.1016/j. rmed.2010.12.022 
Hermans EJ, Henckens MJAG, Roelofs K, Fernández G (2013) Fear bradycardia and activation of the human periaqueductal grey. Neuroimage 66:278-287. https://doi.org/10.1016/j.neuroimage .2012 .10 .063

Jbabdi S, Johansen-Berg H (2011) Tractography: where do we go from here? Brain Connect 1:169-183. https://doi.org/10.1089/brain .2011 .0033

Jeurissen B, Tournier JD, Dhollander T et al (2014) Multi-tissue constrained spherical deconvolution for improved analysis of multishell diffusion MRI data. Neuroimage. 103:411-426. https://doi. org/10.1016/j.neuroimage.2014.07.061

Jones DK, Knösche TR, Turner R (2013) White matter integrity, fiber count, and other fallacies: the do's and don'ts of diffusion MRI. Neuroimage 73:239-254

Keuken MC, Forstmann BU (2015) A probabilistic atlas of the basal ganglia using 7 T MRI. Data Br 4:577-582. https://doi. org/10.1016/j.dib.2015.07.028

Kheradmand A, Zee DS (2011) Cerebellum and ocular motor control. Front Neurol SEP 2:53. https://doi.org/10.3389/fneur.2011.00053

Kong J, Tu P, Zyloney C, Su T (2010) Intrinsic functional connectivity of the periaqueductal gray, a resting fMRI study. Behav Brain Res 211:215-219. https://doi.org/10.1016/j.bbr.2010.03.042. Intrinsic

Koutsikou S, Crook JJ, Earl EV et al (2014) Neural substrates underlying fear-evoked freezing: the periaqueductal grey-cerebellar link. J Physiol 592:2197-2213. https://doi.org/10.1113/jphys iol.2013.268714

Koutsikou S, Watson TC, Crook JJ et al (2015) The periaqueductal gray orchestrates sensory and motor circuits at multiple levels of the neuraxis. J Neurosci 35:14132-14147. https://doi.org/10.1523/ JNEUROSCI.0261-15.2015

Koutsikou S, Apps R, Lumb BM (2017) Top down control of spinal sensorimotor circuits essential for survival. J Physiol 595:41514158. https://doi.org/10.1113/JP273360

Kozlowska K, Walker P, McLean L, Carrive P (2015) Fear and the defense cascade. Harv Rev Psychiatry 23:263-287. https://doi. org/10.1097/HRP.0000000000000065

Lansing RW, Gracely RH, Banzett RB (2009) The multiple dimensions of dyspnea: review and hypotheses. Respir Physiol Neurobiol 167:53-60

Maier-Hein KH, Neher PF, Houde JC et al (2017) The challenge of mapping the human connectome based on diffusion tractography. Nat Commun 8(1):1349. https://doi.org/10.1038/s4146 7-017-01285-x

McCall AA, Miller DM, Yates BJ (2017) Descending influences on vestibulospinal and vestibulosympathetic reflexes. Front Neurol 8:112

McMullan S, Lumb BM (2006) Spinal dorsal horn neuronal responses to myelinated versus unmyelinated heat nociceptors and their modulation by activation of the periaqueductal grey in the rat. J Physiol 576:547-556. https://doi.org/10.1113/jphys iol.2006.117754

Menant O, Andersson F, Zelena D, Chaillou E (2016) The benefits of magnetic resonance imaging methods to extend the knowledge of the anatomical organisation of the periaqueductal gray in mammals. J Chem Neuroanat 77:110-120

Milardi D, Arrigo A, Anastasi G et al (2016a) Extensive direct subcortical cerebellum-basal ganglia connections in human brain as revealed by constrained spherical deconvolution tractography. Front Neuroanat 10:29. https://doi.org/10.3389/fnana .2016 .00029

Milardi D, Cacciola A, Cutroneo G et al (2016b) Red nucleus connectivity as revealed by constrained spherical deconvolution tractography. Neurosci Lett 626:68-73. https://doi.org/10.1016/j.neule t.2016.05.009
Milardi D, Cacciola A, Calamuneri A et al (2017) The olfactory system revealed: Non-invasive mapping by using constrained spherical deconvolution tractography in healthy humans. Front Neuroanat 11:32. https://doi.org/10.3389/fnana.2017.00032

Mobbs D, Yu R, Rowe JB et al (2010) Neural activity associated with monitoring the oscillating threat value of a tarantula. Proc Natl Acad Sci 107:20582-20586. https://doi.org/10.1073/pnas.10090 76107

Moers-Hornikx VMP, Vles JSH, Lim LW et al (2011) Periaqueductal grey stimulation induced panic-like behaviour is accompanied by deactivation of the deep cerebellar nuclei. Cerebellum 10:61-69. https://doi.org/10.1007/s12311-010-0228-z

Nisimaru N, Mittal C, Shirai Y et al (2013) Orexin-neuromodulated cerebellar circuit controls redistribution of arterial blood flows for defense behavior in rabbits. Proc Natl Acad Sci U S A 110:14124-14131. https://doi.org/10.1073/pnas.1312804110

Owen SLF, Heath J, Kringelbach ML et al (2007) Preoperative DTI and probabilistic tractography in an amputee with deep brain stimulation for lower limb stump pain. Br J Neurosurg 21:485490. https://doi.org/10.1080/02688690701558358

Owen SLF, Heath J, Kringelbach M et al (2008) Pre-operative DTI and probabilisitic tractography in four patients with deep brain stimulation for chronic pain. J Clin Neurosci 15:801-805. https ://doi.org/10.1016/j.jocn.2007.06.010

Parker GJM, Alexander DC (2005) Probabilistic anatomical connectivity derived from the microscopic persistent angular structure of cerebral tissue. Philos Trans R Soc Lond B Biol Sci 360:893-902. https://doi.org/10.1098/rstb.2005.163

Parker GD, Marshall D, Rosin PL et al (2013) A pitfall in the reconstruction of fibre ODFs using spherical deconvolution of diffusion MRI data. Neuroimage 65:433-448. https://doi. org/10.1016/j.neuroimage.2012.10.022

Patenaude B, Smith SM, Kennedy DN, Jenkinson M (2011) A Bayesian model of shape and appearance for subcortical brain segmentation. Neuroimage 56:907-922. https://doi.org/10.1016/j. neuroimage.2011.02.046

Qi S, Meesters S, Nicolay K et al (2015) The influence of construction methodology on structural brain network measures: a review. J Neurosci Methods 253:170-182

Rizzo G, Milardi D, Bertino S et al (2018) The limbic and sensorimotor pathways of the human amygdala: a structural connectivity study. Neuroscience 385:166-180. https://doi. org/10.1016/j.neuroscience.2018.05.051

Roberts JA, Perry A, Roberts G et al (2017) Consistency-based thresholding of the human connectome. Neuroimage 145:118129. https://doi.org/10.1016/j.neuroimage.2016.09.053

Roelofs K (2017) Freeze for action: neurobiological mechanisms in animal and human freezing. Philos Trans R Soc B Biol Sci 372:20160206. https://doi.org/10.1098/rstb.2016.0206

Roelofs K, Hagenaars MA, Stins J (2010) Facing freeze. Psychol Sci 21:1575-1581. https://doi.org/10.1177/0956797610384746

Rubinov M, Sporns O (2010) Complex network measures of brain connectivity: uses and interpretations. Neuroimage 52:10591069. https://doi.org/10.1016/j.neuroimage.2009.10.003

Sacchetti B, Baldi E, Lorenzini CA, Bucherelli C (2002) Cerebellar role in fear-conditioning consolidation. Proc Natl Acad Sci 99:8406-8411. https://doi.org/10.1073/pnas.112660399

Sacchetti B, Scelfo B, Tempia F, Strata P (2004) Long-term synaptic changes induced in the cerebellar cortex by fear conditioning. Neuron 42:973-982. https://doi.org/10.1016/j.neuro n.2004.05.012

Sacchetti B, Sacco T, Strata P (2007) Reversible inactivation of amygdala and cerebellum but not perirhinal cortex impairs reactivated fear memories. Eur J Neurosci 25:2875-2884. https ://doi.org/10.1111/j.1460-9568.2007.05508.x 
Sacchetti B, Scelfo B, Strata P (2009) Cerebellum and emotional behavior. Neuroscience 162:756-762

Sillery E, Bittar RG, Robson MD et al (2005) Connectivity of the human periventricular-periaqueductal gray region. J Neurosurg 103:1030-1034. https://doi.org/10.3171/jns.2005.103.6.1030

Smith SM (2002) Fast robust automated brain extraction. Hum Brain Mapp 17:143-155. https://doi.org/10.1002/hbm.10062

Smith SM, Jenkinson M, Woolrich MW et al (2004) Advances in functional and structural MR image analysis and implementation as FSL. Neuroimage 23:S208-S219. https://doi. org/10.1016/j.neuroimage.2004.07.051

Smith RE, Tournier JD, Calamante F, Connelly A (2013) SIFT: spherical-deconvolution informed filtering of tractograms. Neuroimage 67:298-312. https://doi.org/10.1016/j.neuroimage.2012.11.049

Snider R, Eldred E (1951) Electro-anatomical studies on cerebro-cerebellar connections in the cat. J Comp Neurol 95:1-16. https:// doi.org/10.1002/cne. 900950102

Sokolowski K, Corbin JG (2012) Wired for behaviors: from development to function of innate limbic system circuitry. Front Mol Neurosci 5:55. https://doi.org/10.3389/fnmol.2012.00055

Sotiropoulos SN, Jbabdi S, Xu J et al (2013) Advances in diffusion MRI acquisition and processing in the Human Connectome Project. Neuroimage 80:125-143. https://doi.org/10.1016/j.neuroimage .2013 .05 .057

Stoodley CJ, Schmahmann JD (2009) Functional topography in the human cerebellum: a meta-analysis of neuroimaging studies. Neuroimage 44:489-501. https://doi.org/10.1016/j.neuroimage .2008 .08 .039

Stoodley CJ, Schmahmann JD (2010) Evidence for topographic organization in the cerebellum of motor control versus cognitive and affective processing. Cortex 46:831-844. https://doi. org/10.1016/j.cortex.2009.11.008

Stoodley CJ, Schmahmann JD (2016) Functional topography of the human cerebellum. In: essentials of cerebellum and cerebellar disorders: a primer for graduate students, pp 373-381

Strata P (2015) The emotional cerebellum. Cerebellum 14:570-577

Teune TM, van der Burg J, van der Moer J et al (2000) Topography of cerebellar nuclear projections to the brain stem in the rat. Prog Brain Res. 124:141-172. https://doi.org/10.1016/s0079 $-6123(00) 24014-4$

Tournier JD, Calamante F, Connelly A (2007) Robust determination of the fibre orientation distribution in diffusion MRI: nonnegativity constrained super-resolved spherical deconvolution. Neuroimage 35:1459-1472. https://doi.org/10.1016/j.neuroimage .2007.02.016

Tournier JD, Yeh CH, Calamante F et al (2008) Resolving crossing fibres using constrained spherical deconvolution: validation using diffusion-weighted imaging phantom data. Neuroimage 42:617-625. https://doi.org/10.1016/j.neuroimage.2008.05.002

Tournier J-D, Calamante F, Connelly A (2011) Effect of step size on probabilistic streamlines: implications for the interpretation of connectivity analyses. In: proceedings of the international society for magnetic resonance in medicine, p 2019
Tournier JD, Calamante F, Connelly A (2012) MRtrix: Diffusion tractography in crossing fiber regions. Int J Imaging Syst Technol 22(1):53-66. https://doi.org/10.1002/ima.22005

Tovote P, Fadok JP, Lüthi A (2015) Neuronal circuits for fear and anxiety. Nat Rev Neurosci 16:317-331. https://doi.org/10.1038/ nrn3945

Tovote P, Esposito MS, Botta P et al (2016) Midbrain circuits for defensive behaviour. Nature 534(7606):206. https://doi.org/10.1038/ nature 17996

Uğurbil K, Xu J, Auerbach EJ et al (2013) Pushing spatial and temporal resolution for functional and diffusion MRI in the human connectome project. Neuroimage 80:80-104. https://doi.org/10.1016/j. neuroimage.2013.05.012

Van Essen DC, Smith SM, Barch DM et al (2013) The WU-Minn human connectome project: an overview. Neuroimage 80:62-79. https://doi.org/10.1016/j.neuroimage.2013.05.041

van Wijk BCM, Stam CJ, Daffertshofer A (2010) Comparing brain networks of different size and connectivity density using graph theory. PLoS One 5(10):e13701. https://doi.org/10.1371/journ al.pone.0013701

Verstynen T, Jarbo K, Pathak S, Schneider W (2011) In vivo mapping of microstructural somatotopies in the human corticospinal pathways. J Neurophysiol 105:336-346. https://doi.org/10.1152/ jn.00698.2010

Voogd J, Schraa-Tam CKL, Van Der Geest JN, De Zeeuw CI (2012) Visuomotor cerebellum in human and nonhuman primates. In: Cerebellum, pp 392-410

Walker P, Carrive P (2003) Role of ventrolateral periaqueductal gray neurons in the behavioral and cardiovascular responses to contextual conditioned fear and poststress recovery. Neuroscience 116:897-912. https://doi.org/10.1016/S0306-4522(02)00744-3

Watson TC, Cerminara NL, Lumb BM, Apps R (2016) Neural correlates of fear in the periaqueductal gray. J Neurosci 36:1270712719. https://doi.org/10.1523/JNEUROSCI.1100-16.2016

Zhang Y, Brady M, Smith S (2001) Segmentation of brain MR images through a hidden Markov random field model and the expectation-maximization algorithm. IEEE Trans Med Imaging 20:4557. https://doi.org/10.1109/42.906424

Zhang L-L, Wang J-Q, Qi R-R et al (2016a) Motion sickness: current knowledge and recent advance. CNS Neurosci Ther 22:15-24. https://doi.org/10.1111/cns.12468

Zhang X-Y, Wang J-J, Zhu J-N (2016b) Cerebellar fastigial nucleus: from anatomic construction to physiological functions. Cerebellum Ataxias 3:9. https://doi.org/10.1186/s40673-016-0047-1

Zhang Y, Larcher KM-H, Misic B, Dagher A (2017) Anatomical and functional organization of the human substantia Nigra and its connections. Elife 6:e26653. https://doi.org/10.7554/eLife.26653

Publisher's Note Springer Nature remains neutral with regard to jurisdictional claims in published maps and institutional affiliations. 